\title{
Schistosomiasis of the spinal cord: report of 5 cases from Sudan
}

A.D. Salim, ${ }^{7}$ M.A. Arbab, ${ }^{1,2}$ L.A. El Hassan ${ }^{3}$ and A.M. El Hassan ${ }^{4}$

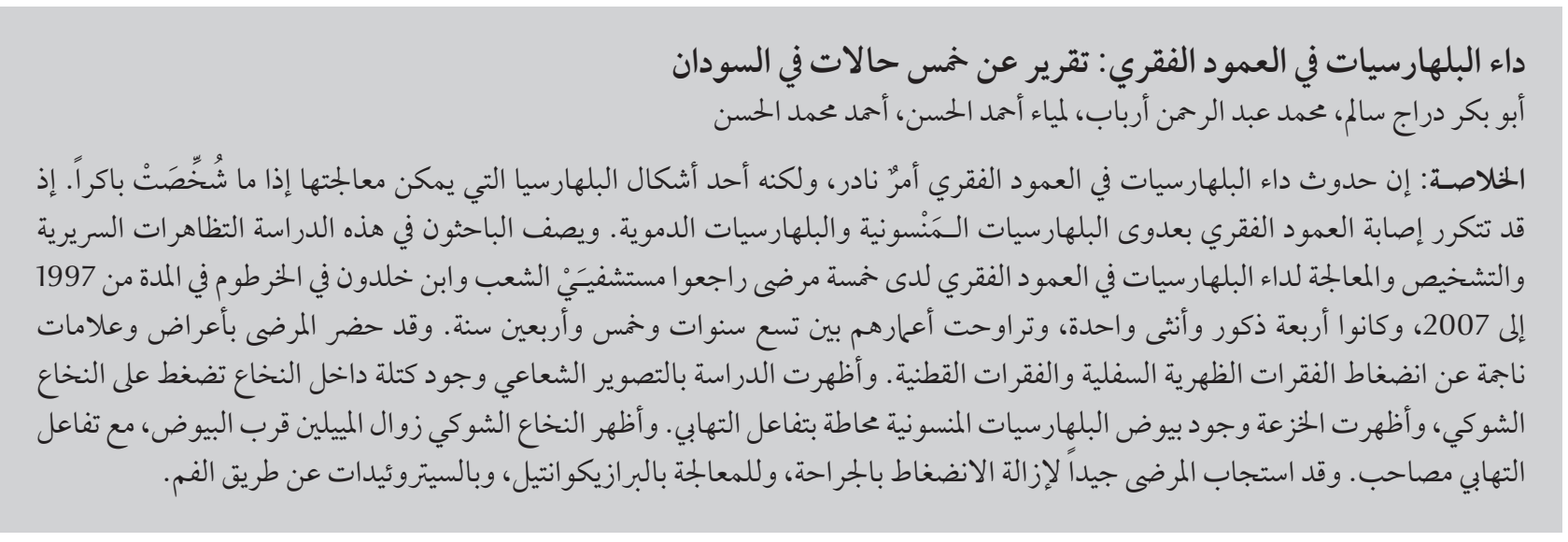

ABSTRACT Schistosomiasis of the spinal cord is an uncommon but potentially curable form of schistosomiasis, if diagnosed and managed early. The spinal cord is more frequently affected in Schistosoma mansoni or S. haematobium infections. This paper describes the clinical manifestations, diagnosis and management of schistosomiasis of the spinal cord in 5 patients attending Shaab and Ibn Khuldoun Hospitals, Khartoum from 1997 to 2007. There were 4 males and 1 female aged 9-45 years. They presented with symptoms and signs due to cord compression at the lower thoracic and lumbar vertebrae. Imaging studies revealed intramedullary masses compressing the cord. Biopsy showed ova of S. mansoni with surrounding inflammatory reaction. The cord showed demyelination near the ova and an associated inflammatory reaction. Patients responded well to surgical decompression and treatment with praziquantel and oral steroids.

\section{Schistosomiase médullaire : rapport sur cinq cas au Soudan}

RÉSUMÉ La schistosomiase médullaire est une forme rare mais potentiellement curable de la schistosomiase, lorsque le diagnostic a été posé au début de l'affection et que la prise en charge a été rapide. Ce sont les infections à Schistosoma mansoni ou à S. haematobium qui s'accompagnent le plus d'une atteinte de la moelle épinière. Le présent article décrit les manifestations cliniques, le diagnostic et la prise en charge de la schistosomiase médullaire chez cinq patients admis dans les hôpitaux Shaab et Ibn Khaldoun de Khartoum entre 1997 et 2007. Âgés de 9 à 45 ans, quatre étaient de sexe masculin et une de sexe féminin. Les motifs de consultation des patients étaient des symptômes et des signes causés par la compression de la moelle épinière au niveau des vertèbres lombaires et thoraciques inférieures. Les examens par imagerie ont révélé des nodules intramédullaires comprimant la moelle. Les biopsies ont mis en évidence des œufs de $S$. mansoni encapsulés par une réaction inflammatoire. La moelle présentait une démyélinisation près de l'œuf associée à une réaction inflammatoire. Les patients ont bien réagi à la décompression chirurgicale, au traitement par praziquantel et aux corticostéroïdes per os.

'Neurosurgery Department, Shaab and Ibn Khuldoun Hospitals, Khartoum, Sudan.

${ }^{2}$ Department of Surgery, Faculty of Medicine, University of Khartoum, Khartoum, Sudan.

${ }^{3}$ School of Medicine, Ahfad University for Women, Omdurman, Sudan.

${ }^{4}$ Institute of Endemic Diseases, University of Khartoum, Khartoum, Sudan (Correspondence to A.M. El Hassan: ahmedelhassan85@gmail.com). Received: 12/10/10; accepted: 02/03/11 


\section{Introduction}

Schistosomiasis is caused by several species of the genus Schistosoma. The main species causing disease in humans are $S$. haematobium, $S$.mansoni and S. japonicum [1]. According to the World Health Organization (WHO) about 200 million people are infected with schistosomiasis worldwide [1]. The adult worms of S. mansoni and S. japonicum live in the mesenteric vascular system of the host, feeding on blood. $S$. haematobium worms are found in the vessels around the urinary bladder. Living adult worms cause no inflammatory response; the main pathology is caused by a granulomatous inflammation around eggs trapped in the tissues $[2,3]$. S. mansoni and S. japonicum that infect the gastrointestinal tract are important causes of hepatosplenic schistosomiasis and portal hypertension $[1,3,4]$. $S$. haematobium infects the urinary tract causing a variety of pathological lesions $[3,5]$.

In Sudan schistosomiasis is a major health problem and the prevalence can reach as high as $50 \%$ in children in some areas [6]. The main endemic foci for S. mansoni in the country are El Gezira State and Bor district $[7,8]$. S. haematobium is endemic along small rivers and in agricultural schemes in many parts of northern Sudan.

One of the less common manifestations of $S$. mansoni infection is spinal cord compression due to deposition of eggs, mainly in the cauda equina, causing neurological deficit $[9,10]$. This paper describes 5 cases of schistosomiasis of the spinal cord encountered in 2 neurosurgery centres in Khartoum.

\section{Case identification}

In 2007, records of 200 cases with cord compression due different causes in El Shaab and Ibn Khuldoun Hospitals, Khartoum, Sudan, were reviewed to retrieve cases diagnosed with schistosomiasis of the spinal cord. The patients were seen between 1997 and 2007 at the Neurosurgery Departments of the hospitals. The information obtained included age, sex, occupation, residence, history of travel to schistosomiasisendemic areas, imaging and laboratory investigations, pathology and treatment.

The study was approved by the Ethical Review Committee of the Institute of Endemic Diseases of the University of Khartoum.

\section{Results}

Of the 200 patients diagnosed as having spinal cord compression, 5 had spinal cord compression due to schistosomiasis. Three patients were investigated by magnetic resonance imaging (MRI) imaging of the spinal cord. In the other 2 patients myelograms of the spinal cord were performed as this was the only available option. Clinical data and the results of imaging are shown in Table 1 . Four of the patients were males and one was a female. Their ages ranged between 9 and 42 years (mean 21 years). Four patients were students and one was an army officer. Their travel history indicated that they had been infected in areas known to be endemic for $S$. mansoni infection in Sudan.

The clinical features in all the patients were remarkably similar. They all suffered from weakness in the lower limbs, incontinence of urine and impaired sensation in the lower limb. The duration of symptoms varied from 2 weeks to 2 months. None had hepatosplenomegaly or portal hypertension. The stools of all patients were positive for S. mansoni eggs. Apart from eosinophilia in 1 patient, other laboratory data were uninformative. MRI images of 3 patients showed swelling of the spinal cord at D12 to L1 or L2 with hyperintense patches in $\mathrm{T} 2$ images. The other 2 patients were investigated by myelogram, which showed spinal cord swelling between D12 and L2. In all patients the provisional diagnosis was a spinal cord space occupying lesion, most probably a tumour

The pathology of the spinal cord masses in all 5 patients showed S. mansoni eggs inside the veins (Figure 1). The majority of the eggs were viable as shown by intact nuclei of the miracidia they contained. Dead eggs showed no miracidial nuclei and some were calcified. Some eggs showed SplendoreHoeppli phenomenon due to immune complexes around them. The spinal cord showed oedema, demyelination and a chronic inflammatory cellular infiltrate with some eosinophils in the Virchow-Robin space (Figure 2).

After laminectomy and confirmation of the schistosomal cause of the

\begin{tabular}{lccccc}
\hline \multicolumn{5}{l}{ Table 1 Clinical and imaging findings of the $\mathbf{5}$ cases of spinal schistosomiasis } \\
Case \# & $\begin{array}{c}\text { Age } \\
\text { (years) }\end{array}$ & Sex & Occupation & $\begin{array}{c}\text { Duration of symptoms } \\
\text { (months) }\end{array}$ & Imaging result \\
1 & 42 & Male & Army officer & 0.5 & MRI: D12-L1 swelling + hyperintense patches \\
2 & 9 & Female & Student & 2 & MRI: D11-L2 swelling + hyperintense patches \\
3 & 22 & Male & Student & 2 & CT myelogram: D12-L1 spinal cord swelling \\
4 & 16 & Male & Student & 1 & CT myelogram: D12-L2 spinal cord swelling \\
5 & 14 & Male & Student & 1.5 & MRI: D12-L1 swelling + hyperintense patches \\
\hline
\end{tabular}

$M R I=$ magnetic resonance imaging; $C T=$ computed tomography . 


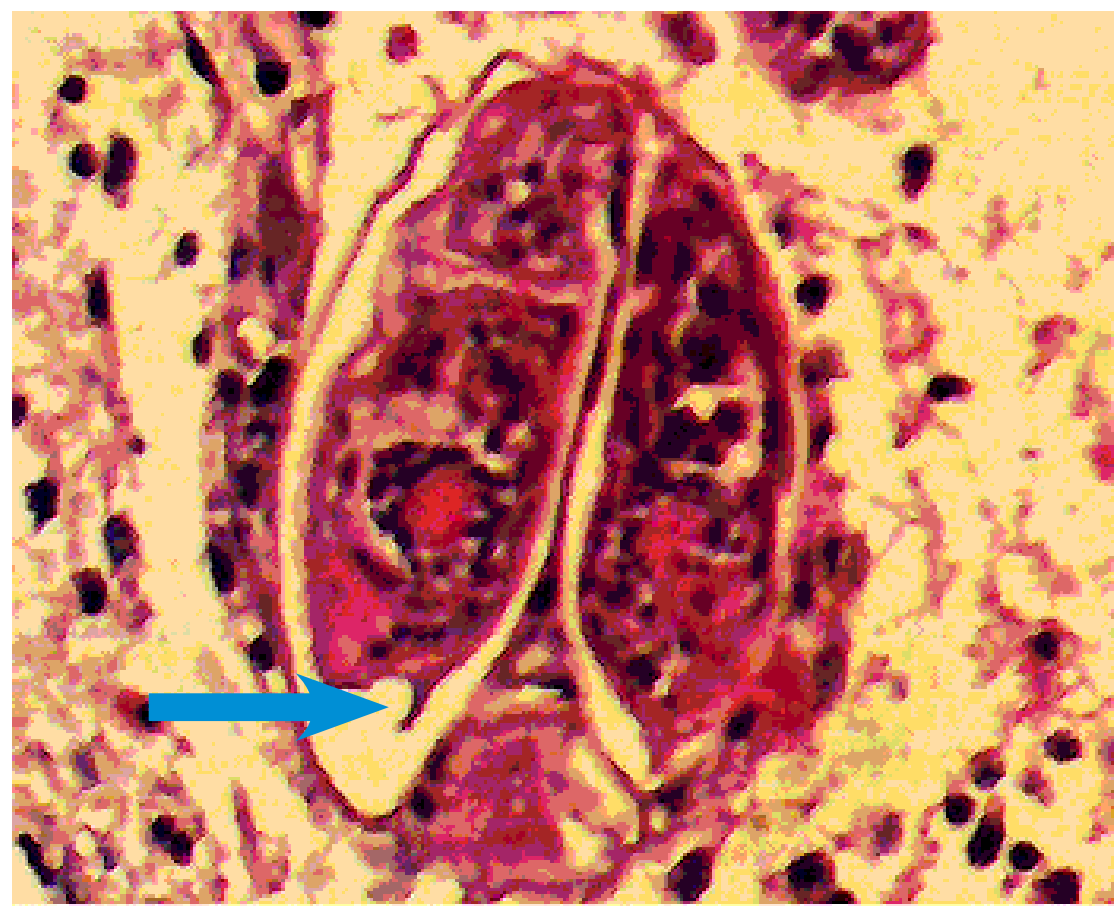

Figure 1 Two schistosomal eggs are seen; the one on the left has a lateral spine (arrow) confirming that it is Schistosoma mansoni (H\&E×40)

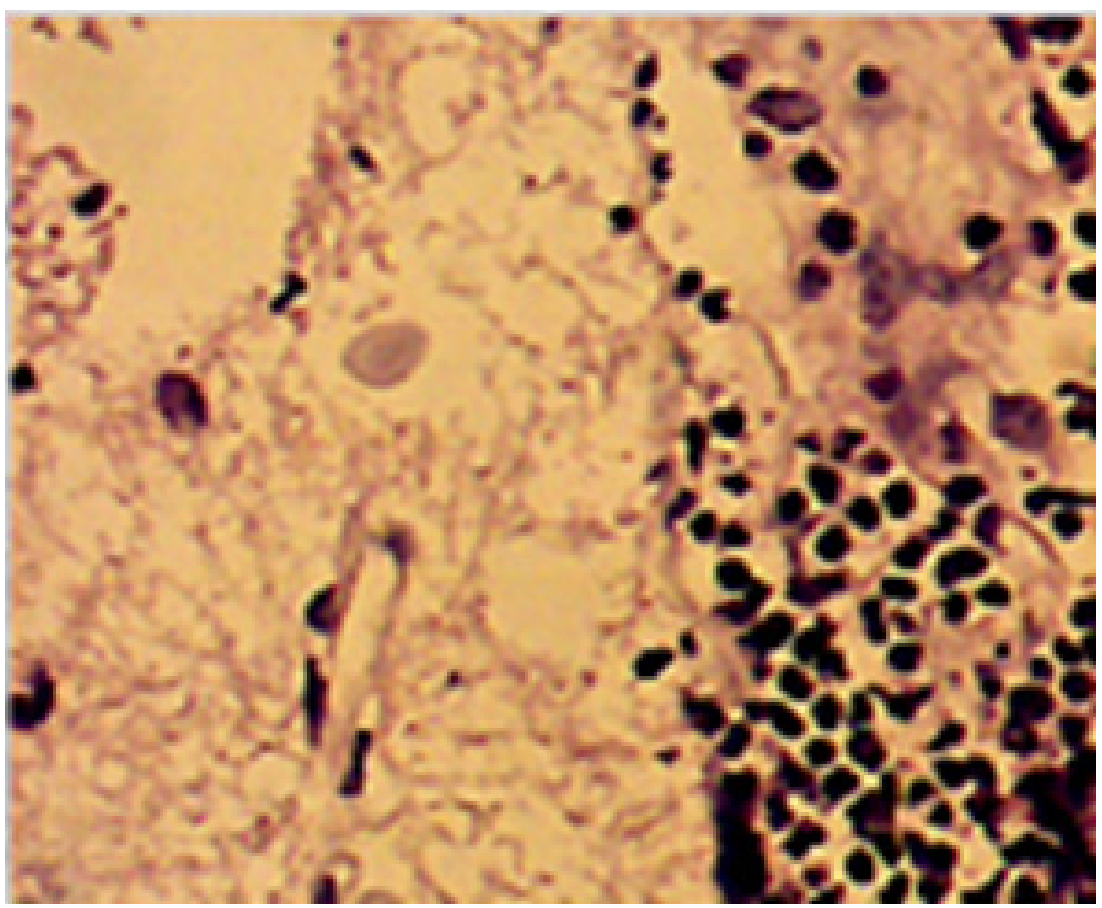

Figure $2 \mathrm{~A}$ focus of chronic inflammatory cellular infiltrate in the white matter of the spinal cord (right of the figure); the inflammation is most probably in a Virchow-Robin space. Note the marked oedema and demyelination of surrounding tissue (H\&Ex40) cord compression, praziquantel was given at a dose of $40 \mathrm{mg} / \mathrm{kg}$ a day in 2 divided doses 6 hours apart for 2 consecutive days. The patients also received prednisolone at a dose of $5 \mathrm{mg}$ daily for 6-12 weeks. All the patients responded well to treatment: 1 fully recovered; in 3 patients the urinary incontinence disappeared and they regained motor power but they still had some loss of sensation; and 1 patient regained bladder function but had only partial improvement of motor power in the lower limbs.

\section{Discussion}

Involvement of the central nervous system may occur with any of the 3 main causes of schistosomiasis: S. mansoni, S. haematobium and S. japonicum. The sites involved are the brain and the spinal cord $[9,10]$. Brain affection is more common with $S$. japonicum while the spinal cord is more frequently affected in S. mansoni or S. hematobium infections. Schistosomal myelopathy tends to occur early after infection and is more likely to be symptomatic than cerebral schistosomiasis. Spinal schistosomal disease causes acute or subacute myelopathy that may be accompanied by polyradiculitis, bowel or bladder dysfunction, paraparesis, paraplegia, lumbosacral pain and sensory disturbances [11].

Lesions in the spinal cord are most common in the lumbar and lower thoracic parts [12]. It is believed that the eggs reach the cord either as a result of embolization through the vertebral venous plexus of Batson or they may be deposited locally by ectopic worms in the vicinity of the cord $[11,12]$. We have shown in serial sections that the eggs appeared to reach the cord via the Virchow-Robin space.

The patients described here had cord compression due to S. mansoni infection. This was confirmed by demonstration of eggs in biopsies of the spinal cord. The damage to the cord is 
attributable to the presence of the eggs and transverse myelitis as evidenced by the demyelination in the cord which was associated with a chronic inflammatory cellular infiltrate around the eggs. The majority of our patients were males. Males are usually more exposed to schistosomiasis infection than females as in rural areas they are more likely to be working in the fields. The symptoms were remarkably similar in all the patients. The diagnosis of cord compression was made on clinical grounds and was confirmed by imaging. The schistosomal etiology was only made after biopsy of the spinal cord lesions. This is true of most cases reported in the literature. Of all 200 patients with cord compression managed by us, only $5(2.5 \%)$ were due to schistosomiasis. Schistosomiasis should be suspected in any patient with cord compression who is resident in an area endemic for schistosomiasis, or one who has visited such an area. Clinical and laboratory evidence of intestinal or urinary schistosomiasis in a patient with brain or cord symptoms should alert the clinician to the possibility of schistosomiasis as a possible cause of the neurological abnormalities.

The treatment of schistosomiasis of the central nervous system is a combination of surgery, antischistosomal drugs and steroids. We treated our patients with $40 \mathrm{mg} / \mathrm{kg}$ a day of praziquantel for 2 days instead of giving the drug for 1 day only. We used this dose over 2 days because we wanted to make certain that the drug would be effective. A patient with spinal cord schistosomiasis was previously treated with praziquantel at $20 \mathrm{mg} / \mathrm{kg}$ for 3 consecutive days with good results [9]. Some patients in other parts of the world were treated with $50 \mathrm{mg} / \mathrm{kg}$ of praziquantel as a single dose along with corticosteroids [13]. The steroids were continued without praziquantel for 6 months [13]. Praziquantel kills the adult worms and reduces the egg load [14]. Corticosteroids may reduce the granulomatous inflammation, thereby preventing further tissue destruction; there is evidence that they also reduce ova deposition. The patients also underwent surgery for decompression of the spinal cord

In conclusion schistosomiasis should be included in the differential diagnosis of space occupying lesions involving the brain or cord in areas endemic for schistosomiasis. The treatment of cord compression due to schistosomiasis includes both surgery and drug therapy. The role of surgery is decompression, particularly in large lesions and to provide material for pathological diagnosis. This should then be followed by antischistosomal drugs and steroids.

\section{Acknowledgements}

We acknowledge the help of Dr E.B. Mohamed and Dr Samira Mirghany of El Shaab Hospital for the compilation of data. We are indebted to Miss Ameera Adam for helping with the preparation of the manuscript.

\section{References}

1. Gryseels B et al. Human schistosomiasis. Lancet, 2006, 368:1106-1118.

2. Scrimgeour EM, Gajdusek DC. Involvement of the central nervous system in Schistosoma mansoni and S hematobium: a review. Brain, 1985, 108:1023-1038.

3. Lucey DR, Maguire JH. Schistosomiasis. Infectious Disease Clinics of North America, 1993, 7:635-653.

4. Kheir MM et al. Mortality due to schistosomiasis mansoni: a field study in Sudan. American Journal of Tropical Medicine and Hygiene, 1999, 60:307-310.

5. Sharfi AR, El Sir S, Beleil O. Squamous cell carcinoma of the urinary bladder. British Journal of Urology, 1992, 69:369-371.

6. Abd El Rahman M et al. Prevalence of intestinal schistosomiasis in New Halfa scheme, Eastern Sudan. Khartoum Medical Journal, 2010, 3(2):448-451.

7. Mudawi $\mathrm{H}$, Ali Y, El Tahir M. Prevalence of gastric varices and portal hypertensive gastropathy in patients with Symmers periportal fibrosis. Annals of Saudi Medicine, 2008, 28:42-44.

8. Omer AH et al. Hycanthone trial in the treatment of Schistosoma mansoni infection in the Sudan. Journal of Tropical Medicine and Hygiene, 1972, 75:165-168.
9. Van Leusen H, Perquin WV. Spinal cord schistosomiasis. Journal of Neurology, Neurosurgery, and Psychiatry, 2000, 69:690-691.

10. Pittela JE, Lana-Peixoto MA. Brain involvement in hepatosplenic schistosomiasis mansoni. Brain, 1981, 104:621-632.

11. Nascimento-Carvalho CM, Moreno-Carvalho OA. Neuroschistosomiasis due to Schistosoma mansoni: A review of pathogenesis, clinical syndrome and diagnostic approaches. Revista do Instituto de Medicina Tropical de Sao Paulo, 2005, 47:179-184.

12. Saleem S, Belal Al, El-Ghandour NM. Spinal cord schistosomiasis: MRI imaging appearance with surgical and pathologic correlation. AJNR. American Journal of Neuroradiology, 2005, 26:1646-1654.

13. Silva LC et al. Treatment of schistosomal myeloradiculopathy with praziquantel and corticosteroids and evaluation by magnetic resonance imaging: a longitudinal study. Clinical Infectious Diseases, 2004, 39:1618-1624.

14. Liang YS et al. Adult worm tegumental damage and egggranulomas in Praziquantel-resistant and -susceptible Schistosoma mansoni treated in vivo. Journal of Helminthology, 2002, 76:327-333. 